\title{
DOS EXPERIENCIAS DE APLICACIÓN DEL NEXO INVESTIGACIÓN-DOCENCIA EN CIENCIAS SOCIALES: LA PERSPECTIVA DEL DOCENTE UNIVERSITARIO
}

\section{TWO EXPERIENCES ON THE APPLICATION OF THE RESEARCH-TEACHING NEXUS IN SOCIAL SCIENCES: THE PERSPECTIVE OF THE UNIVERSITY TEACHER}

Antonio D. Cámara Hueso (Universidad de Jaén) ${ }^{1}$

Francisco Barros Rodríguez (Universidad de Jaén) ${ }^{2}$

José Miguel Martínez Carrión (Universidad de Murcia) ${ }^{3}$

Begoña Candela Martínez (Universidad de Murcia) ${ }^{4}$

\section{Resumen:}

Hay al menos tres planos desde los que el nexo metodológico investigación-docencia puede contemplarse como factor estratégico en el proceso de aprendizaje universitario: 1) el de la productividad y competitividad científico-académica a nivel institucional; 2) el de la capacitación individual de cara a la integración en mercados laborales crecientemente competitivos y 3) el de la mejora de la eficiencia en el planteamiento de proyectos y gestión de recursos en los sectores público y privado. En los tres planos resulta evidente la contribución potencial de una docencia interactiva y experimental que ceda protagonismo a los estudiantes en la consecución de competencias.

El objetivo de este trabajo es presentar y discutir dos experiencias inspiradas en estas metodologías que se desarrollan en asignaturas de grados de Ciencias Sociales en las Universidades de Jaén y Murcia.

En torno a dichas experiencias se comentan algunos recursos de aprendizaje aplicados en distintas fases del curso y con distintas finalidades: fundamentos de diagnóstico a partir de la resolución de problemas de investigación, asimilación práctica de conceptos, técnicas de generación y de recopilación de información, y elaboración de soportes mediáticos para la presentación y difusión de resultados de investigación. Finalmente se presentan y discuten, desde el punto de vista docente, algunos resultados de aprendizaje obtenidos, las principales dificultades detectadas en la aplicación de la metodología y los avances obtenidos en las competencias establecidas originalmente.

Palabras clave: Metodología docente, innovación docente, aprendizaje interactivo, docencia orientada a la investigación, nexo investigación-docencia.

Códigos JEL: A22, I23

Abstract:

The methodological model known as research-teaching nexus can be considered as an strategic factor for the learning process at university in at least three different ways, namely:

\footnotetext{
1 adcamara@ujaen.es, Universidad de Jaén.

2 fbarros@ujaen.es, Universidad de Jaén.

3 jcarrion@um.es, Universidad de Murcia.

4 bcandela@um.es, Universidad de Murcia.

Recibido 24 de septiembre de 2019. Aceptado 3 de diciembre de 2019.
} 
1) in terms of scientific and academic productivity and competitiveness at the institutional level; 2) in terms of individual training addressed to the successful integration in labor markets which are increasingly competitive and 3) for the improvement of the efficiency on project planning and resource management in both the public and the private sectors. Under any of the former perspectives, it is apparent the potential contribution of interactive- and experimental-guided teaching in transferring prominence to students during the attainment of a number of abilities and competences.

The aim of this paper is to present and discuss two cases inspired by this type of teaching methodologies. These experiences are carried out in subjects of Social Sciences degrees at the Universities of Jaen and Murcia (Spain).

Around these experiences some tools applied over diverse stages of the learning program and with diverse objectives are commented, namely: foundations for diagnose base on research problem solving, practical understanding of concepts, data collection-generation techniques, and means of presentation and dissemination of research findings. The main constraints and handicaps that students have to face during the development of their projects are commented as well. Finally, some learning outcomes attained together with some difficulties that were found over the application of this methodology and the advances on the targeted competences are discussed.

Key words: teaching methodology, teaching innovation, interactive learning, research-based teaching, research-teaching nexus.

JEL codes: A22, I23

\section{INTRODUCCIÓN}

El fomento del pensamiento crítico durante la realización de los estudios universitarios es parte esencial del proceso de adquisición y mejora de las habilidades y competencias específicas, tal y como se define en el marco del Espacio Europeo de Educación Superior (Tuning Project, 2007). Además, el desarrollo de la capacidad de análisis crítico forma parte de un enfoque integral de la educación estrechamente asociado a los conceptos que conforman la visión contemporánea del desarrollo social y humano. Es decir, concebir la educación como un instrumento de transformación de la realidad de las personas tanto en el plano individual como social (valores, comportamientos y estilos de vida insertados en sociedades más libres, pacíficas, seguras, democráticas y sostenibles) (UNESCO, 2002). Recurriendo al moderno paradigma del desarrollo humano (Sen, 1989; Griffin, 2001), la educación superior planteada en los anteriores términos conlleva un logro o funcionalidad que abre un amplio abanico de nuevas capacidades en el proceso de retroalimentación de la mejora de las condiciones de vida individuales y sociales (PNUD, 1990; Sen, 2005; Nussbaum, 2011). También, específicamente, en la capacidad de adaptación y la toma de control sobre determinadas situaciones en un contexto como la sociedad actual caracterizado por la complejidad de las relaciones sociales. No en balde, términos de la Sociología contemporánea como sociedad líquida (Bauman, 2000) o sociedad del riesgo (Beck, 1992) han hecho fortuna aludiendo, grosso modo, a que el cambio y la inestabilidad han pasado a formar parte de los propios rasgos estructurales de la sociedad. Nos enfrentamos a una realidad social en la que los perfiles estructurales que en un pasado no muy lejano constituían pautas o guías en el comportamiento de las personas, además de determinadas certezas en sus expectativas de vida, están hoy muy difuminados cuando no han desaparecido. En este escenario social, caracterizado también por su dimensión global y por una competitividad alta y creciente, la iniciativa, la versatilidad y el desarrollo continuo de capacidades adaptativas, mucho más que 
la formación especializada, constituyen activos importantes del capital humano. De ahí que el enfoque proactivo de la actividad docente en el espacio de educación superior (que precede a la incorporación de las personas a los mercados laborales) se convierta, más que en una opción, en una necesidad para los estudiantes.

El logro de capacidades o competencias específicas relacionadas con el análisis crítico de la realidad social constituye uno de los objetivos estratégicos de cualquier iniciativa de innovación docente. De este modo, no solo resulta necesario atender a los medios instrumentales del aprendizaje sino también a sus fines últimos. Por tal motivo entendemos que la innovación docente ha de contemplarse como un modo distinto de hacer las cosas pero también, fundamentalmente, como un modo diferente de plantear la finalidad del proyecto docente (Santos et al., 2012; Carbonell, 2015; Martín \& Barba, 2016; Fernández, 2017).

En los apartados que siguen, se expone la naturaleza teórico-metodológica del denominado nexo o modelo investigación-docencia junto con el desarrollo específico aplicado de esta modalidad de docencia en el ámbito universitario. Esto se hace a través de la descripción de dos experiencias desarrolladas en el ámbito de las Ciencias Sociales en las Universidades de Jaén y Murcia. Los resultados de estas experiencias son discutidas desde el punto de vista de los docentes y el trabajo se cierra con algunas conclusiones.

\section{EL MODELO INVESTIGACIÓN-DOCENCIA EN EL CONTEXTO DE LAS METODOLOGÍAS DOCENTES ALTERNATIVAS}

Podríamos coincidir en que las metodologías docentes emergentes convergen en una forma más interactiva (respecto a un modelo docente de tipo "magistral") de entender la docencia y en un fondo de desarrollo de la capacidad de análisis crítico y de aplicación versátil del conocimiento adquirido por parte de los estudiantes. En esta línea de innovación podrían citarse metodologías como el aula invertida (Lage \& Platt, 2000; O'Flaherty \& Phillips, 2015), el design thinking (Glen, et al., 2014), el aprendizaje basado en proyectos (Lee, et al., 2014), el aprendizaje cooperativo (Tadesse \& Gillies, 2015), el aprendizaje basado en competencias (Lacey \& Murray, 2015), el aprendizaje basado en investigación (Hutchings, 2007a, 2007b), el aprendizaje basado en problemas (Yew \& Goh, 2016), la movilización del conocimiento o knowledge mobilization (Levin, 2011, 2013), o la enseñanza situada (Díaz-Barriga, 2006). Digamos que la enseñanza basada en u orientada a la investigación no es en sí una metodología docente con principios teórico-prácticos propios sino una modalidad de práctica docente bastante transversal a las metodologías citadas; si se quiere, una arena de experimentación proclive a la aplicación de buena parte de las metodologías docentes alternativas que han ido cobrando carta de naturaleza durante las últimas décadas. Se ha empleado el término research-teaching nexus (Healey et al., 2010; González et al., 2016) para referir un modelo de enseñanza pensado para fortalecer el vínculo entre la investigación y la docencia en los centros universitarios. Este modelo, orientado por el profesorado, permite a los estudiantes poner en práctica actividades propias del ámbito científico en el transcurso de su aprendizaje.

Dicho lo anterior, existe una notable variedad terminológica relacionada con ese nexo y con su aplicación en el aula. Esto es comprensible si se tienen en cuenta las múltiples vías y posibilidades de plantear una metodología docente y un proceso de aprendizaje dirigidos por la investigación. Algunos trabajos han planteado taxonomías formales al respecto (es decir, en función de las distintas formas de integración docencia-investigación que componen el modelo research-teaching nexus) (Griffiths, 2004; Healey, 2005a, 2005b; Brew, 2010, 2013; Levy \& Petrulis, 2012). En concreto, Griffiths (2004) plantea que podrían distinguirse las siguientes modalidades metodológicas dentro del modelo a partir de un estudio llevado a cabo en cuatro universidades del Reino Unido: 
- Research-led teaching, en donde los estudiantes aprenden a partir de los resultados de investigación obtenidos (y relatados) por el profesor o por otros investigadores. El interés se halla en entender los resultados en lugar de los procesos de investigación.

- Research-oriented teaching, en donde los estudiantes adquieren competencias metodológicas mediante el aprendizaje de los procesos de investigación en, por ejemplo, talleres metodológicos. El interés recae tanto en los resultados como en los procesos de investigación.

- Research-based teaching, en donde los estudiantes aprenden a partir de su participación en actividades basadas en la investigación como, por ejemplo, llevar a cabo una pequeña investigación (detectar problemas, determinar objetivos, recabar y analizar datos, presentar resultados). El interés recae en las actividades de investigación (y la experiencia del profesor) en lugar de en la adquisición de contenidos.

- Research-informed teaching, en donde los estudiantes adquieren competencias investigadoras a partir de una investigación sistemática del proceso de enseñanzaaprendizaje en sí mismo. El interés recae en el uso de la investigación pedagógica ${ }^{5}$.

En la práctica, lo habitual es la coexistencia y complementariedad de varios enfoques pertenecientes al modelo (Pan, et al., 2014). Además, no hay una aplicación definida de cada uno de ellos en particular puesto que resulta siempre bastante importante la integración/adaptación del método al contexto académico en el que nos ubiquemos. Esto incluye desde el nivel de conocimientos previos del alumnado y el curso de impartición hasta la situación contractual del profesorado, los recursos disponibles, y la disciplina académica de aplicación de la metodología, pasando por las propias características del sistema educativo. En conjunto, estos factores no han propiciado una aplicación generalizada de este modelo docente en España en el ámbito de las Ciencias Sociales. Por tanto, creemos de interés compartir algunas experiencias que, a modo de adaptaciones específicas del nexo investigación-docencia, se van desarrollando en distintas universidades españolas. El objetivo de este trabajo es describir y comentar dos de esas aplicaciones docentes desarrolladas en dos titulaciones de la rama de Ciencias Sociales en las Universidades de Jaén (UJA) y Murcia (UMU). Se exponen distintas posibilidades de integración (aplicaciones y adaptaciones metodológicas) del modelo investigación-docencia en el aula y se discuten algunos logros y limitaciones de esta metodología desde el punto de vista docente en el contexto de aplicación de las experiencias. En cuanto a los objetivos de las experiencias docentes en sí, ambas se centran en el desarrollo de la capacidad de análisis crítico y de la proactividad en el terreno laboral mediante la adquisición de competencias básicas adaptativas: diagnóstico de situación y diseño e implementación de proyectos.

La experiencia docente de la UJA se desarrolla en el Grado en Gestión y Administración Pública -GAP- con estudiantes cuyos desempeños profesionales van a producirse en la Administración Pública en la mayoría de los casos. La experiencia descrita para la UMU corresponde a estudiantes del Grado de Marketing cuya inserción laboral se producirá mayoritariamente en el sector privado.

5 Healey (2005a, 2005b), a partir de la conceptualización de Griffiths, estableció otra clasificación. En concreto, reemplazó el enfoque research-informed teaching por uno nuevo que denominó research-tutored teaching. En este enfoque los estudiantes participan en cursos o tutorías en las que discuten con los profesores sobre temas de investigación. Un ejemplo sería discutir en grupo y de forma crítica algún artículo científico tras su lectura. 


\section{METODOLOGÍA}

Como se ha señalado, la aplicación del nexo investigación-docencia en el aula abarca potencialmente todo el espectro de métodos, técnicas y aplicación secuencial de las fases clásicas del proceso de producción y transferencia de conocimiento científico. En los casos que se describen, las adaptaciones teóricas y técnicas pertenecen en lo fundamental al ámbito de las Ciencias Sociales. Los proyectos en los que se inscriben estas adaptaciones responden a un diseño tradicional de investigación, con la peculiaridad de que los estudiantes no solo "piensan” el proyecto sino que además lo ejecutan bajo dos criterios principales: aprendizaje autónomo y trabajo colaborativo.

Ambas experiencias docentes comparten bastantes elementos en su desarrollo secuencial $\mathrm{y}$, dado que las aplicaciones metodológicas son en esencia complementarias dentro del nexo investigación-docencia, se ha optado por la siguiente fórmula expositiva. Para ambos casos se describen brevemente el contexto y los objetivos en función de las competencias establecidas en las respectivas guías docentes. En cuanto a las fases de ejecución de los proyectos, la inicial (de concreción de estudios de caso), se comenta en detalle para la experiencia realizada en la UMU mientras que para el proyecto de la UJA se describen tanto el planteamiento como algunos resultados y problemáticas relacionados con los módulos de aprendizaje diseñados. En cuanto a los hitos finales se ha optado por desarrollar los contenidos de la experiencia de la UMU.

\subsection{Grado de GAP de la UJA}

La metodología se desarrolla en la asignatura Métodos y Técnicas de Investigación Social de Segundo Curso del Grado de GAP de la UJA desde el curso académico 2016-2017. Se trata de una asignatura obligatoria en el plan de estudios de la titulación. En los últimos cuatro cursos académicos, el número de matriculados ha oscilado entre 20 y 30 con una asistencia regular que podría calificarse de media-baja (entre el 40 por cien y el 60 por cien; durante los cursos a los que se refiere la experiencia, la asistencia a clase no fue obligatoria ni puntuable). Todas las actividades puntuables así como los distintos materiales de apoyo y resúmenes de las intervenciones del profesorado en clase estuvieron disponibles en el espacio virtual de la asignatura, en la plataforma ILIAS. Como singularidad destacable de los grupos de estudiantes, una proporción no despreciable de los mismos ya trabaja como personal funcionarial o como personal interino de larga duración en distintos niveles y áreas de la Administración Pública. Éste es uno de los factores a los que el sistema de evaluación de la asignatura pretende responder planteándose el objetivo de lograr cinco puntos (sobre diez) para superar la materia, con independencia de cómo se obtengan esos puntos: proyecto de investigación y/o evaluación final. El proyecto se compone de entre cuatro y cinco actividades evaluables que se secuencian a lo largo del curso contribuyendo a la consecución del hitotérmino descrito más abajo. El conjunto de actividades enmarcadas en el proyecto tiene un valor de cinco puntos. Por su parte, la evaluación final consiste en una prueba de contenidos teóricos aplicados (dos supuestos o problemas de investigación relacionados con las distintas fases de una investigación social y que pueden estar relacionados temáticamente con el proyecto realizado). Estos supuestos de investigación se complementan con un ejercicio de preguntas tipo test dicotómicas (verdadero o falso). Esta evaluación puntúa un máximo de otros cinco puntos.

Nos parece interesante señalar que, al ser preguntados de manera informal por sus expectativas profesionales, la gran mayoría de los estudiantes declara aspirar a superar unas oposiciones e integrarse en la estructura de la Administración Pública. Este horizonte, junto con unos planes docentes muy volcados hacia contenidos jurídicos-administrativos, hace que a priori la asignatura (impartida desde el área de Sociología de la UJA) sea un elemento algo 
exótico o extraño, cuando no incómodo y percibido como poco útil por la mayoría del alumnado. Las competencias y resultados de aprendizaje incluidos en la guía docente de la asignatura son los siguientes:

Competencias:

- E14 Saber aplicar a la gestión pública las principales herramientas de la estadística.

- E15 Saber aplicar las estrategias de investigación sociológica.

- E4 Conocer los fundamentos de la Sociología y la dimensión social de la gestión pública.

- G1 Capacidad de análisis y síntesis.

- G2 Reflexión crítica.

- G5 Gestión de información.

- G8 Comunicación y comprensión interpersonal.

- G9 Saber expresarse en público para la defensa de trabajos individuales o grupales.

Resultados de aprendizaje:

- El alumno sabe gestionar la información, reflexiona críticamente sobre la misma, tiene capacidad de organización y planificación.

- El alumno sabe adaptarse a las nuevas circunstancias que van surgiendo, tiene capacidad de comprensión y comunicación en las relaciones entre personas y toma decisiones.

- El alumno se expresa en público con el fin de defender tanto trabajos individuales como en grupo, adoptando en ocasiones posición de líder.

- El alumno conoce los fundamentos de la Sociología y sabe aplicar las estrategias de investigación sociológica, así como las principales herramientas de la estadística.

- El alumno sabe gestionar la información y documentación administrativa.

- El alumno conoce las aplicaciones informáticas para la gestión administrativa y financiera y conoce el entorno.

- El alumno se expresa en público para la defensa de trabajos individuales o grupales con soltura.

- El alumno comprende la organización y el funcionamiento de las Administraciones Públicas y su dinámica en la nueva gestión pública.

Para comenzar, hay que señalar que el hecho de que la asignatura se denomine "Métodos y técnicas de investigación social” no implica necesariamente la aplicación del nexo o modelo investigación-docencia. Por ejemplo, no es lo mismo definir o explicar (y asimilar por parte de los estudiantes) el concepto de hipótesis de investigación a través del empleo de un manual académico al uso (metodología tradicional) que a través del razonamiento autónomo y colaborativo sobre la experiencia o problema práctico de investigación sobre el que se ha decidido trabajar de partida (aplicación metodológica del nexo investigación-docencia). De manera similar, el desarrollo de un tema central de la asignatura como es la metodología cuantitativa y de la técnica de la encuesta puede realizarse en abstracto o de manera magistral (metodología tradicional), o bien hacerse de una forma más interactiva y participativa (p.ej. partiendo de la formulación de preguntas de investigación sobre un tema elegido y tratando de dar respuesta a dichas preguntas mediante el procesamiento y análisis de microdatos de encuestas o bien mediante la generación de información primaria a través del diseño y aplicación de un cuestionario ad hoc). Muchos otros ejemplos podrían citarse. La asignatura seguiría siendo "Métodos y Técnicas de Investigación Social” en cualquier caso, pero la metodología docente puede o no responder al modelo del nexo investigación-docencia. 
En el desarrollo de la asignatura, los estudiantes tienen como referente o hito final del curso la elaboración y presentación de un trabajo de iniciación a la investigación cuyo formato y requisitos toman, en lo esencial, lo estipulado para los TFGs en la Facultad de Ciencias Sociales y Jurídicas de la UJA. La investigación se plantea como un estudio de caso dentro de un área de análisis general que habitualmente tiene que ver con una realidad o problemática social en la que esté involucrada la Administración Pública (preferentemente en base a sus intereses potenciales desde el punto de vista profesional, pero no es obligatorio que así sea). El trabajo se desarrolla secuencialmente a lo largo de un cuatrimestre en módulos de aprendizaje tutorizados por el profesorado (Tabla 1).

TABLA 1. ESQUEMA SECUENCIAL DE DESARROLLO DEL PROGRAMA DE CURSO BASADO EN LAS FASES DEL PROYECTO DE INVESTIGACIÓN

\begin{tabular}{|c|c|c|}
\hline $\begin{array}{l}\text { Denominación } \\
\text { módulo }\end{array}$ & Contenidos asociados & $\begin{array}{l}\text { Variante } \\
\text { metodológica } \\
\text { aplicada }\end{array}$ \\
\hline $\begin{array}{l}\text { Módulo } 1 \\
\text { Planteamiento del } \\
\text { estudio de caso y } \\
\text { elaboración teórico- } \\
\text { conceptual del } \\
\text { problema }\end{array}$ & $\begin{array}{l}\text { - Concreción del estudio de caso } \\
\text { - Formulación de preguntas de investigación, } \\
\text { objetivos e hipótesis } \\
\text { - Labor de documentación científica previa } \\
\text { - Técnicas de referenciación/citación }\end{array}$ & $\begin{array}{l}\text { Research-based } \\
\text { teaching Research-led } \\
\text { teaching }\end{array}$ \\
\hline $\begin{array}{l}\text { Módulo } 2 \\
\text { Abordaje } \\
\text { instrumental de los } \\
\text { objetivos de la } \\
\text { investigación }\end{array}$ & $\begin{array}{l}\text { - Revisión y acceso a repositorios de } \\
\text { información - Estudio y familiarización con } \\
\text { metadatos, datos agregados y/o microdatos } \\
\text { - Formación básica en procesamiento y análisis } \\
\text { descriptivo de datos agregados y/o microdatos } \\
\text { mediantes seminarios ad hoc }\end{array}$ & $\begin{array}{l}\text { Research-based } \\
\text { teaching Research-led } \\
\text { teaching } \\
\text { Research-oriented } \\
\text { teaching }\end{array}$ \\
\hline $\begin{array}{l}\text { Módulo } 3 \\
\text { Discusión crítica de } \\
\text { resultados }\end{array}$ & $\begin{array}{l}\text { - Revisión de hipótesis de investigación y } \\
\text { objetivos } \\
\text { - Replanteamiento de preguntas de } \\
\text { investigación } \\
\text { - Formulación de conclusiones o argumentos } \\
\text { principales para la discusión }\end{array}$ & $\begin{array}{l}\text { Research-based } \\
\text { teaching Research-led } \\
\text { teaching }\end{array}$ \\
\hline $\begin{array}{l}\text { Módulo } 4 \\
\text { Estrategias de } \\
\text { presentación pública } \\
\text { de los resultados }\end{array}$ & $\begin{array}{l}\text { - Presentación pública en formatos visuales } \\
\text { - Estructuración de los contenidos de la } \\
\text { investigación en un informe o documento de } \\
\text { trabajo }\end{array}$ & $\begin{array}{l}\text { Research-based } \\
\text { teaching Research-led } \\
\text { teaching } \\
\text { Research-oriented } \\
\text { teaching }\end{array}$ \\
\hline
\end{tabular}


A continuación, se expone sucintamente el contenido de cada uno de los módulos junto con algunos comentarios relativos a la experiencia obtenida durante el proceso de aprendizaje de los estudiantes.

Módulo 1. Planteamiento del estudio de caso y elaboración teórico-conceptual del problema.

Se trata, sin duda, de la fase de aprendizaje que plantea mayores dificultades a los estudiantes por varios motivos. El principal, es el hecho de que el proyecto de investigación es preconcebido como un trabajo de prácticas en grupo al modo en que la mayoría de ellos lo ha practicado en la enseñanza pre-universitaria. Esto es, como un ensayo muy generalista y que habitualmente abusa en la tarea de documentación y redacción de las fuentes más al uso disponibles en Internet (p.ej., noticias de prensa, de radio y de televisión, blogs personales, Wikipedia y similares). Así, es interesante comprobar que la tarea más ardua a la que se enfrentan es la formulación de preguntas específicas de investigación que lleven al establecimiento de objetivos específicos e hipótesis que perfilen y den sentido a un estudio de caso. Por tanto, en este módulo resultan de utilidad algunas estrategias de concreción de un estudio de caso y, de cualquier modo, es la fase que requiere más atención tutorial puesto que se corre el riesgo de que sin un buen planteamiento y concreción iniciales del problema de investigación, el resto de las actividades y tareas de curso discurran sin rumbo. Dada la corta duración de la asignatura, los numerosos puntos de fuga que caracterizan todo inicio de una investigación han de ser acotados y reducidos de una manera más rápida y operativa, para lo cual resulta imprescindible la labor de tutorización y el feedback inter-grupal en clase.

Módulo 2. Abordaje instrumental de los objetivos de la investigación.

La experiencia en este módulo es que, una vez superadas las dificultades en torno al núcleo teórico-conceptual de la investigación, los estudiantes se ven más atraídos por sus proyectos ya que se desarrolla la capacidad de responder a preguntas de investigación formuladas por ellos mismos; esto es, mediante la búsqueda y acceso a datos secundarios o también (más excepcionalmente debido a las limitaciones de tiempo) vía generación de datos primarios mediante alguna de las técnicas incluidas en el temario de la asignatura (encuesta, observación contextual o entrevista en profundidad, fundamentalmente). El interés viene, a menudo, acompañado del vértigo natural a la generación de conocimiento científico y a uno de sus derivados: el error. Por este motivo resulta básica la labor de refuerzo anímico del profesorado: alumbrar conocimiento científico se basa precisamente en el ensayo y el error tomando como protocolo básico la verificación de las hipótesis de investigación que se han formulado por su parte. Obvia decir que la evaluación del desempeño de los estudiantes en este sentido no puede ni debe basarse en la ortodoxia y en la corrección formal de los análisis realizados, sino en la coherencia de las pesquisas de investigación a partir de las preguntas y objetivos que plantearon en sus proyectos.

Inicialmente, el principal hándicap del desarrollo autónomo de los análisis es la poca o nula destreza en el manejo de herramientas informáticas de procesamiento y análisis de datos. La principal ventaja y aliciente es que la formación específica en el uso de estos softwares, aunque sea a nivel básico, pone en sus manos un instrumento cuyas potencialidades son percibidas rápidamente por su parte. En este sentido, como puede entenderse, en este punto es fundamental permitir la experimentación aun a costa de la heterodoxia o del simple error de procedimiento. 
Módulo 3. Discusión crítica de resultados.

Si las dos primeras fases son de tensionamiento de la atención y de las capacidades previas de los estudiantes, este módulo es de distensión en ambos sentidos. Se trata esencialmente de replantear los argumentos iniciales del trabajo y comprobar los avances realizados: qué se ha aprendido y qué se puede pensar o suponer a la luz de lo que dicen los resultados obtenidos. Los estudiantes aprenden algo esencial en esta fase como es la necesidad de que los resultados no sean obtenidos con pocos días u horas de antelación respecto a la fecha de la presentación y/o entrega del hito-término del proyecto. De nuevo, la labor del docente en este sentido es asesorar convenientemente sobre el tiempo y los esfuerzos que han de invertir los grupos en cada módulo. Así se previene que tanto la elaboración teórica del problema como la fase de análisis se prolonguen más de lo prudente. El objetivo con ello es permitirles reflexionar sobre los resultados y logros obtenidos en la investigación.

Lo habitual en esta fase es que los estudiantes se enfrenten a una relativa frustración, particularmente cuando no se verifican sus hipótesis, los resultados resultan contradictorios o sienten "no haber descubierto nada". Como consecuencia, una de las inclinaciones más frecuentes es a desnaturalizar los resultados hasta hacer que estos digan lo que se esperaba que dijeran, al precio que sea (tentación que, por otra parte, no es ajena al desempeño profesional de la investigación en Ciencias Sociales). Normalmente, una semana de distanciamiento respecto a los resultados obtenidos y a la labor de investigación realizada resulta un procedimiento útil de cara a la revisión final de los proyectos y a la mejora de la calidad de los mismos.

Módulo 4. Estrategias de presentación pública de los resultados.

Cada grupo dispone de un máximo de 15 minutos para llevar a cabo las presentaciones. Durante el curso, las explicaciones del docente han sido ilustradas mediante presentaciones en formato PPT o similar en las que imágenes, gráficos, diagramas y esquemas han sido los formatos predominantes, con poca relevancia del texto. El problema principal de fondo detectado en este módulo es la tendencia a "querer decirlo y explicarlo todo". Por esta razón, el trabajo de orientación tutorial se dirige principalmente a aportar criterios que apoyen una correcta selección autónoma de contenidos de los proyectos que sirvan para la presentación. Sobre este punto se entrará en más detalle en el proyecto realizado por los estudiantes de la UMU.

Como puede suponerse, cada uno de los módulos descritos está inscrito en un temario que no prescinde del desarrollo de algunos conceptos y técnicas básicas de investigación social. No obstante, la estructuración de ese temario y la asimilación de conocimientos están siempre asociados al trabajo de investigación que se está realizando. De manera transversal al desarrollo de los módulos de aprendizaje se aplican dos recursos docentes complementarios: discusión y resolución de problemas y el recurso Made in UJA.

Lo primero no es otra cosa que la discusión colectiva en torno a breves supuestos de investigación adaptados al desarrollo de media o de una sesión y cuyo objetivo se hace corresponder a la fase del trabajo de investigación en el que se encuentran los estudiantes. Estas actividades también pueden abarcar o referirse a varias fases de ese trabajo a modo de repaso. Aquí se les enfrenta desde al diagnóstico de una problemática sobre la que teóricamente tienen capacidad de gestión e intervención en un determinado nivel de la Administración Pública, hasta al diseño de estrategias de intervención en función de distintas hipótesis de investigación y resultados obtenidos, pasando por la operacionalización de conceptos en forma de indicadores. 
Por su parte, Made in UJA es un complemento docente de descompresión, en tanto que se hace al grupo partícipe del diseño y ejecución de proyectos de investigación en curso en la Universidad de Jaén (research-led teaching). En concreto, se abordan proyectos en los que los docentes han sido investigadores principales o miembros del equipo de investigación. Estas intervenciones intercaladas en el desarrollo del curso, y que también se coordinan en cuanto a su contenido con el desarrollo secuencial de los módulos, presentan un valor doble.

En primer lugar, los estudiantes conocen la intrahistoria de una investigación, incluyendo problemas, contratiempos y anécdotas diversas que, a diferencia de lo publicado en tono académico como resultados de investigación, contribuye a desmitificar y sacar de un universo iniciático la labor de investigación. Como es natural, lo anterior incluye el hecho de presentar y comentar los pequeños y grandes errores que los investigadores profesionales cometemos en nuestro quehacer.

En segundo lugar, el efecto que estas intervenciones tiene sobre estudiantes pertenecientes a una universidad pequeña, y modesta en cuanto a su peso y reputación científica, es ciertamente positivo. Así, por ejemplo, dentro del módulo 4, Made in UJA sirve para presentar productos de investigación elaborados en distintos formatos (artículos, pósteres, documentos de trabajo, entradas de blog, presentaciones en medios, etc.) y que han sido discutidos en distintos foros académico-científicos nacionales e internacionales.

\subsection{Grado de Marketing de la UMU}

Esta experiencia se desarrolla en la asignatura de Historia Económica (Primer Curso del Grado de Marketing de la UMU). Comparte con el anterior caso el hecho de que se trata de una materia outsider en un grado donde el peso fundamental de la carga docente lo ocupan materias de Marketing como la dirección y gestión de marketing, la investigación de mercados y la comunicación de marketing, marketing digital, etc.

La aplicación metodológica del nexo investigación-docencia en esta asignatura lleva vigente tres cursos académicos (comienza en el 2016-2017) y la calificación de los hitos del proyecto (informe y póster) pondera con un 20 por cien en la calificación final. Un conjunto de tareas y actividades prácticas asociadas al desarrollo del proyecto (p.ej. la consulta y aprovechamiento de bases de datos y materiales oportunos para la investigación grupal), pondera hasta un 30 por cien. El resto (50 por cien) lo conforma un examen teórico compuesto por dos partes: preguntas tipo test y preguntas de desarrollo.

Las competencias o capacidades que se reflejan en la guía docente de la asignatura son las siguientes:

\section{Competencias:}

- Competencia básica 3. Que los estudiantes tengan la capacidad de reunir e interpretar datos relevantes (normalmente dentro de su área de estudio) para emitir juicios que incluyan una reflexión sobre temas relevantes de índole social, científica o ética.

- Competencia básica 4. Que los estudiantes puedan transmitir información, ideas problemas y soluciones a un público tanto especializado como no especializado.

- Competencia transversal y de materia 2. Buscar, organizar, gestionar e interpretar informaciones cualitativas y cuantitativas referidas a la evolución económica de la empresa.

- Competencia de la titulación CG3. Ser capaz de gestionar la información y el conocimiento en su ámbito disciplinar, incluyendo saber utilizar como usuario las herramientas básicas en TIC.

- Competencia de la titulación G7. Desarrollar habilidades de iniciación a la investigación. 
- Competencia Específica CE20. Ser capaz de identificar las fuentes de información económica y de los mercados relevantes y su contenido.

- Competencia 4. Adquisición de destrezas para el análisis de realidades económicas complejas pasadas y presentes.

- Competencia de la titulación CG6. Ser capaz de trabajar en equipo y relacionarse con otras personas del mismo o distinto ámbito profesional.

- Competencia de la titulación CG8. Tener capacidad de análisis y síntesis en entornos relacionados con el marketing.

- Competencia Específica CE 17. Ser capaz de analizar y comprender el comportamiento de los consumidores y compradores organizacionales desde la perspectiva de marketing.

- Competencia 5. Dominio de procedimientos, instrumentos y terminología de la ciencia histórica para el análisis económico.

- Competencia Específica CE 18. Ser capaz de planificar, desarrollar y redactar proyectos de investigación de mercados.

- Competencia Específica CE 23. Ser capaz de discernir el comportamiento ético de la empresa. Identificar comportamientos éticos de la empresa y discernir su sentido, valor y aplicabilidad.

En cuanto a los resultados de aprendizaje se basan en el conocimiento del carácter dinámico y cambiante de los procesos económicos, de las instituciones comerciales y del marketing; adquisición de destrezas para entender la complejidad de los procesos económicos en el largo plazo y analizar críticamente los fenómenos económicos del pasado y del presente.

Hay que decir que, en el caso del sistema educativo regional de Murcia, el nexo investigación-docencia en el ámbito universitario presenta el aliciente o la necesidad de dar continuidad a un creciente protagonismo de las actividades de investigación en la enseñanza secundaria (es creciente el número de estudiantes matriculados en itinerarios del Bachillerato de Investigación regulado en el sistema educativo regional en 2007). De ahí el interés de reforzar ese nexo desde el comienzo de los grados universitarios ${ }^{6}$.

La actividad docente en la asignatura se plantea bajo la forma de proyecto colaborativo inter-grupal al que se ha asignado una denominación genérica: "Made in Spain, Made in Murcia: El desarrollo de las empresas familiares. Una historia del marketing empresarial”. Es decir, el planteamiento de la docencia se basa en la elaboración colectiva de la historia del marketing empresarial mediante el encaje y la discusión de distintos estudios de caso elegidos por cada grupo de trabajo. El objetivo del proyecto vuelve a ser el estímulo del aprendizaje del estudiante mediante la investigación autónoma tutorizada. En este caso, al hito-término del trabajo-presentación grupal se añade un hito-término de carácter inter-grupal: una colección de carteles o pósteres de investigación que a la vez servirá de contexto expositivo para la explicación-defensa pública de las investigaciones realizadas.

Cabe decir al respecto que, si bien la realización de pósteres en el mundo académico para presentar trabajos científicos está bien difundida desde hace décadas (Bavdekar et al., 2018), es en los últimos tiempos cuando este sencillo formato ha despertado el interés como herramienta para reforzar el aprendizaje y la formación del alumnado, particularmente en metodologías activas de aprendizaje. Digamos, no obstante, que su uso en la docencia universitaria española es relativamente poco frecuente (Pons et al., 2018; Sánchez et al.,

\footnotetext{
${ }^{6}$ En Andalucía también se llevan a cabo algunas iniciativas para incorporar la labor científica a las etapas educativas pre-universitarias desde el ámbito público. Por ejemplo, el programa “Andalucía Profundiza”, que consiste en la realización de proyectos de investigación en los centros educativos y que está dirigido tanto a alumnos de Primaria como de Secundaria.
} 
2016) y, más aún, entre el alumnado de primer curso. Como se refleja en trabajos anteriores (Rossi, 2018) la presentación en póster de los resultados de un trabajo original realizado por estudiantes es una herramienta de red efectiva y un medio de comunicar de manera articulada la investigación. En el caso que nos ocupa, y tratándose de un proyecto del Grado en Marketing, nos parecía especialmente pertinente usar este recurso comunicativo cuya virtud de aumentar el interés y la atención del público está demostrada.

Por su parte, el hito grupal es, en esencia, el mismo que en la anterior experiencia descrita: la elaboración de una breve monografía o informe estructurado de manera similar al TFG. Las condiciones formales de la entrega del informe y de su defensa en formato póster se instruyen por los docentes a través del aula virtual de la asignatura debiendo subirse a la aplicación en formato $p d f$ en ambos casos.

El proyecto se organiza en grupos reducidos de estudiantes (cuatro por regla general). Los proyectos grupales se enmarcan en este caso en una temática definida como es la historia empresarial y se concretan en estudios de caso basados en empresas españolas o murcianas de origen familiar. Estas empresas comparten trayectorias de crecimiento y expansión y se trata de que los estudiantes exploren los determinantes de la función empresarial en perspectiva diacrónica con la posibilidad de abarcar desde los comienzos de la Revolución Industrial en España hasta el contexto actual de globalización socioeconómica.

Para la concreción de los proyectos y su ulterior desarrollo se proporcionan a los estudiantes algunos criterios o pautas generales así como algunos recursos de apoyo que responden tanto al núcleo teórico de los trabajos como al aparato empírico-instrumental. Así, temática o conceptualmente, los apartados que pueden cubrir total o parcialmente los trabajos son:

- Orígenes y desarrollo de la empresa: búsqueda de noticias o registros sobre la ubicación y los cambios experimentados por la empresa a lo largo del tiempo en áreas clave como el empleo, la producción o la comercialización-exportación.

- El entorno (geográfico, económico, social, ambiental y cultural).

- Las etapas de la firma empresarial: coyunturas históricas en su proceso de crecimiento (etapas de expansión, etapas de reconversión, etapas de reestructuración o crisis).

- El empresariado y la estructura directiva: orígenes sociales y culturales, transmisión intergeneracional familiar, aspectos sobre la formación de los ejecutivos y directivos profesionales, características de la gestión empresarial, tipo de sociedades (limitadas, anónimas, etc.)

- Dimensión de los mercados y procesos de internacionalización.

- Cambios en las formas de organización del trabajo y las relaciones laborales: cualificación de la mano de obra, procesos de automatización, inversión en capital humano y formación, inversión en investigación e innovación, responsabilidad social corporativa, etc.

Desde el punto de vista más instrumental, los proyectos cubren los requisitos curriculares propios de la disciplina de Historia Económica así como de las competencias establecidas en la guía docente como, por ejemplo, el manejo de bases de datos empresariales (fuentes secundarias) y de fuentes históricas (primarias) o la construcción de series de largo plazo de las principales variables socioeconómicas de la función empresarial (esencialmente en lo referido a tamaño o dimensión). Por ejemplo, los estudiantes han de explorar y familiarizarse con tres recursos o repositorios de información disponibles en la UMU como son: 
- DUNS 100.000. Se trata de un directorio de empresas de INFORMA D\&B que contiene la información comercial y de marketing de las 100.000 mayores compañías de España y las 20.000 mayores de Portugal en función de su volumen de ventas ${ }^{7}$.

- SABI. Es el Sistema de Análisis de Balances Ibéricos, una herramienta de información financiera y de business intelligence que ofrece la información de balances de más de 1,3 millones de empresas ${ }^{8}$.

- ALIMARKET (desde 1982). Publicación periódica disponible en la hemeroteca de la Facultad de Economía y Empresa de la $\mathrm{UMU}^{9}$.

En el curso 2018-2019, los grupos de trabajo definieron un total de 39 proyectos sobre otras tantas empresas de diversos sectores (Tabla 2).

Asimismo se recomendaba la práctica (y se proporcionaban nociones generales) de análisis DAFO. Ésta es una herramienta analítica clásica de la situación de una empresa e igualmente aplicable a proyectos: se analizan características internas (debilidades y fortalezas) y características externas (amenazas y oportunidades) en una matriz cuadrada.

Cada proyecto produjo un póster que sintetizaba los aspectos fundamentales del diseño y la implementación de la investigación y sobre el cual se desarrollaban las presentaciones públicas de los mismos. De hecho, como se ha mencionado, el póster (además del trabajo redactado) constituía el hito principal y la palanca instrumental y motivacional del curso dado el atractivo de este formato para la difusión y transferencia de resultados.

Como puede suponerse, se dedicaron durante el curso sesiones técnicas específicas con el fin de capacitar a los estudiantes para la realización de los pósteres y también se proporcionaron ejemplos de pósteres realizados por el Grupo de Investigación de Historia Económica de la UMU los cuales fueron previamente presentados en distintos foros académico-científicos nacionales e internacionales. Se planteó a los estudiantes la estructura temática básica que habitualmente se plasma en un formato como éste (secciones del póster), esto es: a) los antecedentes o la trayectoria histórica de la cuestión planteada, b) las preguntas de investigación (brecha de conocimiento), c) los métodos o las fuentes, d) los resultados, e) las conclusiones y d) referenciación de citas, financiación, agradecimientos, etc.). No obstante, se optó por flexibilizar al máximo el formato tanto para estimular la creatividad como para dar cabida a las variantes y singularidades que cada proyecto hubiera presentado en su ejecución y resultados.

Cada grupo de estudiantes hizo una defensa pública de las pesquisas de investigación realizadas. Tras esta presentación se dedicó un tiempo para preguntas planteadas por el resto de grupos con el fin de estimular los debates. Como aspecto novedoso, la colección de pósteres dio lugar a una exposición pública y al otorgamiento de premios a los mejores pósteres. La exposición estuvo visible en el vestíbulo principal de la Facultad para todos los estudiantes y el personal de la universidad. Este tipo de actividad sirve para reconocer el esfuerzo realizado por los estudiantes y visibilizar el trabajo que se lleva a cabo en la asignatura.

\footnotetext{
${ }^{7}$ http://www.duns100000.com/ [23/09/2019].

${ }^{8}$ https://sabi.bvdinfo.com [23/09/2019].

${ }^{9}$ https://www.alimarket.es/ [23/09/2019].
} 


\section{TABLA 2. LISTADO DE EMPRESAS INVESTIGADAS EN LOS PROYECTOS DE PRIMER CURSO DE MARKETING DE LA UMU EN EL AÑO ACADÉMICO 2018-2019}

\begin{tabular}{|c|c|c|}
\hline Firma empresarial & Año de fundación & Sector \\
\hline Abengoa & 1941 & Infraestructuras, energía \\
\hline Agrolimen & 1937 & Alimentación \\
\hline Barceló & 1931 & Turismo \\
\hline Camper & 1975 & Calzado \\
\hline Campofrío & 1952 & Alimentación \\
\hline Casa Tarradellas & 1976 & Alimentación \\
\hline Chupa-Chups & 1958 & Alimentación \\
\hline Codorniu & 1772 & Bebidas \\
\hline CONSUM & 1975 & Distribución \\
\hline El Corte Inglés & 1940 & Distribución \\
\hline El Mosca & 1965 & Transportes \\
\hline El Pozo & 1954 & Alimentación \\
\hline Estrella Levante & 1963 & Bebidas \\
\hline Famosa & 1957 & Juguetes \\
\hline Font Vella & 1946 & Bebidas \\
\hline Freixenet & 1889 & Bebidas \\
\hline García Carrión & 1890 & Bebidas \\
\hline García Vaquero & 1962 & Alimentación \\
\hline Grupo Leche Pascual & 1969 & Alimentación \\
\hline Hefame & 1950 & Cooperativa Farmacéutica \\
\hline Hero-Alcantarilla & 1922 & Alimentación \\
\hline Inditex-Zara & $1963(1975)$ & Textil \\
\hline Juver & 1962 & Bebidas \\
\hline Larios & 1866 & Bebidas \\
\hline Licor 43 & 1945 & Bebidas \\
\hline Mahou & 1890 & Bebidas \\
\hline Mango & 1984 & Textil \\
\hline Mercadona & 1977 & Alimentación \\
\hline MIVISA & 1972 & Envases metálicos \\
\hline Nutrexpa & 1940 & Alimentación \\
\hline Panrico \& Donuts & 1962 & Alimentación \\
\hline Postres Reina & 1960 & Alimentación \\
\hline Primafrío & 1968 & Transportes \\
\hline Roca & 1917 & Cerámica (baños) \\
\hline Seur & 1942 & Paqueteria urgente \\
\hline Solán de Cabras & 1920 & Bebidas \\
\hline Sol-Meliá & 1950 & Turismo \\
\hline Tous & 1920 & Joyería \\
\hline UNIASA \& Puleva & 1954 & Alimentación \\
\hline
\end{tabular}

Fuente: elaboración propia. 
Finalmente, estábamos especialmente interesados en analizar el comportamiento de los estudiantes durante las presentaciones en público. Como sabemos, este elemento o componente de la actividad constituye habitualmente un déficit en nuestro sistema educativo siendo una parte importante de las metodologías basadas en el nexo investigación-docencia. En la siguiente matriz se presenta a modo de sistema de rúbricas un balance general de las presentaciones de proyecto realizadas por los estudiantes (Tabla 3).

\section{TABLA 3. MATRIZ DE RÚBRICAS EN LA AUTOEVALUACIÓN DE LOS RESULTADOS DEL PROYECTO EN TORNO AL HITO INTERGRUPAL (EXPOSICIONES PÚBLICAS DE PÓSTERES)}

\begin{tabular}{|c|c|}
\hline Aspectos positivos & Aspectos a mejorar \\
\hline \multicolumn{2}{|l|}{ Estructura presentación } \\
\hline $\begin{array}{l}\text { - Señalan los objetivos y las secciones de que } \\
\text { consta el trabajo. } \\
\text { - Destacan los resultados y presentan las } \\
\text { conclusiones. }\end{array}$ & $\begin{array}{l}\text { - Presentación demasiado extensa y poco clara. } \\
\text { - A los ponentes les falta dominio de la materia } \\
\text { que exponen. }\end{array}$ \\
\hline $\begin{array}{l}\text { Coordinación: } \\
\text { - Control del tiempo por los miembros del grupo } \\
\text { - El ponente recibe la colaboración de los } \\
\text { compañeros de grupo (ayuda en la presentación de } \\
\text { los resultados o de algún problema técnico que se } \\
\text { subsana con rapidez y eficiencia; } \\
\text { - El ponente tiene colaboración del resto del grupo } \\
\text { en presentación de materiales o de productos de la } \\
\text { empresa que se distribuyen en la sala. }\end{array}$ & • Falta de coordinación entre compañeros. \\
\hline $\begin{array}{l}\text { Actitud del ponente: } \\
\text { - Serenidad. } \\
\text { - Control de su tiempo. } \\
\text { - Claridad y fluidez expositiva. } \\
\text { - Es ameno y deleita a los oyentes. } \\
\text { - Hay dinamismo e interacción con el público. } \\
\text { - Expresión correcta (verbaliza o expresa ideas } \\
\text { correctas, emplea conceptos e ideas de forma } \\
\text { efectiva y apropiada. }\end{array}$ & $\begin{array}{l}\text { - Habla con la voz baja } \\
\text { - habla muy rápido } \\
\text { come chicle durante la exposición } \\
\text { no controla sus nervios } \\
\text { repite mucho la misma idea } \\
\text { no mantiene el contacto visual con el público } \\
\text { utiliza muletillas. }\end{array}$ \\
\hline $\begin{array}{l}\text { Control del tema/materia a presentar: } \\
\text { • Utilización de un lenguaje adecuado. } \\
\text { • No leer pantalla o documento. }\end{array}$ & $\begin{array}{l}\text { - Hay errores estadísticos y erratas en los } \\
\text { resultados que presentan. } \\
\text { - Mira demasiado la pantalla del ordenador o } \\
\text { documentos. Apenas dirige la mirada a la } \\
\text { audiencia. }\end{array}$ \\
\hline $\begin{array}{l}\text { Formato de la presentación: } \\
\text { • Síntesis adecuada, buena estructura, letra clara, } \\
\text { cuadros o esquemas no muy recargados y } \\
\text { atractivos visualmente. }\end{array}$ & $\begin{array}{l}\text { - La información está mal estructurada, letra } \\
\text { pequeña, mala elección del color de la letra } \\
\text { respecto al fondo, mucho texto y muchos } \\
\text { colores. }\end{array}$ \\
\hline
\end{tabular}


Sin duda, el planteamiento inicial del proyecto objetivado en la elaboración de un producto final y su soporte mediático (por ejemplo el póster) es un importante elemento de dinamización del proceso de aprendizaje en cuanto que hito de referencia en las fases inicial e intermedia del proyecto. También en cuanto que producto tangible e instrumento de difusión científica del mismo. Ha de señalarse que una de las premisas fundamentales de nuestro trabajo es la proyección de la labor realizada por los estudiantes y la percepción de un producto final de relevancia y utilidad social, científica y/o académica por parte de los mismos. En el logro de este objetivo mediático se impone hoy día indudablemente la utilización de recursos asociados a las nuevas tecnologías y las redes sociales. Dicho esto, en términos instrumentales, el reconocimiento y la autovaloración de la utilidad de las investigaciones realizadas puede contemplar distintas técnicas, todas compatibles con la utilización y difusión a través de TIC. En concreto hemos expuesto el caso de la realización y presentación de pósteres, un soporte mediático tradicional que favorece la práctica de técnicas de presentación clásicas (presenciales) con otras tan diversas como la exposición y obtención de feedback mediante herramientas como el blog, las wikis, etc.

\section{DISCUSIÓN}

En este trabajo se han descrito dos experiencias de innovación docente inspiradas en el nexo investigación-docencia. Éstas se desarrollan en grados de la rama de Ciencias Sociales de las universidades de Jaén y Murcia. La valoración de las mismas responde a la percepción de los docentes involucrados.

Las distintas variantes metodológicas del nexo investigación-docencia nacen del sustrato de las llamadas metodologías activas de aprendizaje. En concreto, comparten bastantes características con el ampliamente teorizado y practicado Aprendizaje Basado en Proyectos (ABP) como, por ejemplo, la co-creación de competencias, el trabajo autónomo y colaborativo, la cooperación y feedback inter-grupal, etc. También con la movilización del conocimiento o knowledge mobilization (Levin, 2011, 2013), la cual trata de convertir el conocimiento generado en conocimiento práctico: una muestra, orientada hacia nuestro objeto de trabajo, sería la vinculación de la producción científica con su uso efectivo en el ámbito docente universitario. O en el caso de la enseñanza situada (Díaz-Barriga, 2006), en la que el aprendizaje se contextualiza en la propia profesión: por ejemplo, en una asignatura con la que el alumno aprenda desarrollando una investigación aplicada. No obstante, el nexo investigación-docencia tiene la especificidad de refererirse a un modelo de enseñanza que se centra principalmente en fortalecer ese vínculo o nexo. En dicho propósito tienen cabida buena parte de las metodologías docentes anteriormente mencionadas (aula invertida, design thinking, aprendizaje basado en proyectos, aprendizaje cooperativo, aprendizaje basado en competencias, knowledge mobilization, enseñanza situada, etc.). Por ello, más que el encuadre de las experiencias en una u otra variante de estas metodologías, el principal interés de la práctica docente descrita en el presente trabajo radica en poner en valor la investigación como instrumento de interacción en el aula, es decir, como vía de transferencia de responsabilidad y protagonismo a los estudiantes durante el proceso de aprendizaje. Esto incluye la inmersión ad hoc en el rol de investigadores (diseño, ejecución y transferencia de conocimientos) así como el recurso sistemático a la investigación por parte de los docentes en la labor de transmisión y asimilación de contenidos teórico-prácticos.

Algunos de los beneficios del teaching-research nexus para los estudiantes han sido señalados por la literatura existente, a saber: a) el estímulo del compromiso hacia la investigación; b) la percepción de la investigación como una actividad valiosa en su formación; c) la incorporación natural de los estudiantes en la comunidad científica a través de su participación tanto en proyectos de investigación como en espacios de discusión; d) el desarrollo de competencias que tienden a ser contempladas como complejas entre el 
alumnado, mejorando así su rendimiento académico general; e) la potencial ayuda para abrir y/o esclarecer las salidas profesionales de los estudios cursados (Zamorski, 2002; Brew, 2003; Healey, 2005b; Hunter et al. 2007; Schapper \& Mayson, 2010; Böttcher \& Thiel, 2018; Galbraith \& Merrill, 2012; Smyth et al., 2016; Visser-Wijnveen et al., 2016). Nuestras apreciaciones coinciden en lo fundamental con lo expuesto y también con las recogidas del lado de los estudiantes en trabajos anteriores: valoran positivamente la participación en procesos de enseñanza basados en la investigación (Brew, 2006; Elton, 2001; Griffiths, 2004; Healey et al., 2007). No obstante, en este punto debemos hacer dos observaciones.

La primera y principal es la limitación de este trabajo a la hora de captar las impresiones de los estudiantes. Si bien nos hemos interesado de manera oficiosa por su opinión acerca de las adaptaciones y recursos metodológicos utilizados, no se han aplicado instrumentos específicos de evaluación de la experiencia al margen de las encuestas generales sobre la labor docente del profesorado (no adaptadas a la evaluación de distintos aspectos de esta metodología en concreto y/o su comparación con otras metodologías de aprendizaje). Por tanto, ésta nos parece una vía importante y necesaria de desarrollo de una investigación futura sobre el rendimiento logrado con la aplicación de esta metodología: aspectos mejor valorados, aspectos mejorables y carencias a subsanar desde el punto de vista de los estudiantes.

La segunda observación se refiere a la naturaleza o motivaciones de la penetración del nexo investigación-docencia en las universidades españolas. Al respecto, es necesario apuntar que la inserción progresiva de la investigación en la docencia tiene que ver principalmente con dos factores. En primer lugar, con la relevancia que la investigación ha adquirido como factor de competitividad en el propio currículo docente así como a nivel institucional, es decir, para las universidades. Si bien las actividades de docencia e investigación se han conformado siempre como piezas esenciales dentro de la propia dinámica de los centros de educación superior, es evidente que en países como España el acceso a la carrera docente nunca había sido tan dependiente de la actividad y productividad investigadora como de un tiempo a esta parte. Hasta tal punto es así, que en las últimas décadas la investigación ha alcanzado mayor importancia que la docencia en ese sentido (Brew, 2006). Este cambio ha priorizado la faceta investigadora frente a la docente y tiene su razón de ser en la creciente presión que las universidades y el profesorado reciben para la generación de conocimiento medible, esto es, objetivable en términos de rendimiento científico a través de productos en revistas y editoriales de impacto (Guzmán-Valenzuela \& Barnett, 2013). Así, sin entrar a valorar a fondo estos aspectos, la reputación individual (del profesorado) e institucional (de las universidades) dependen cada vez en mayor grado de dicha productividad y de su reflejo en "índices o indicadores de calidad” (por ejemplo, en el caso de las Ciencias Sociales, Journal Citation Report -JCR- o Scimago Journal \& Country Rank-SJR-). Por lo tanto, no puede pasarse por alto que un primer mecanismo de penetración de la investigación en la docencia obedece a un perfil emergente de docente formado en el mundo de la investigación y forjado en la conocida lógica anglosajona del publish or perish. Si lo contemplamos de este modo, la innovación docente en el sentido apuntado en este trabajo podría considerarse en buena medida como un producto derivado o proceso colateral de los cambios introducidos en el sistema de acceso a los puestos de docencia universitaria; y, por consiguiente, no como el resultado de una apuesta estratégica por la introducción y el fomento de dichas metodologías por parte de las universidades.

Lo dicho no es incompatible con lo que también sería deseable desde nuestro punto de vista: la renovación de las metodologías docentes mediante la creciente introducción de elementos del consabido modelo teaching-research nexus por parte de ese perfil de profesorado y también por parte de un profesorado que accedió a sus puestos por otro sistema de méritos. Añadamos que el binomio investigación-docencia aplicado en el aula facilita a los 
académicos la realización de sus funciones docentes de forma más coherente con los criterios de productividad científica que se están imponiendo.

Otra ventaja que ha sido apuntada es la de la contribución de estas metodologías a mantener un conocimiento actualizado por parte del profesorado acerca de los avances teórico-metodológicos de su respectiva disciplina (Jensen, 1988). En este sentido, este modelo docente permitiría conciliar dos visiones o valoraciones de los estudiantes respecto a la figura del docente-investigador que no pocas veces se han enfrentado. Nos referimos a que algunos estudios han concluido que los estudiantes ven positivamente el hecho de tener docentes con carreras investigadoras destacadas (Zamorski, 2002). Sin embargo, otros estudios apuntan que a veces los estudiantes perciben una menor dedicación (y vocación) docente por parte de un profesorado más preocupado por engrosar su producción científica y, por ende, su competitividad y prestigio en la academia (Jenkins et al., 1998).

Desde nuestro punto de vista (el de profesores universitarios involucrados en la investigación), no cabe duda de que las experiencias descritas constituyen un factor de realización personal y profesional. También hemos percibido claramente que, una vez superados los condicionantes y recelos comunes ante estas metodologías por parte del alumnado, las competencias y resultados de aprendizaje reflejados en las guías docentes no solo son alcanzados por la mayoría sino que, dada la naturaleza de los mismos y su habitual asociación a la capacidad crítica de análisis, pueden ser contrastados de una manera mucho más coherente y fehaciente que mediante metodologías docentes tradicionales.

\section{CONCLUSIONES}

Compartimos en lo esencial las conclusiones positivas obtenidas en los trabajos previos citados aunque los resultados obtenidos en las experiencias descritas son en cualquier caso aparentes y parciales en cuanto que requieren de concreción instrumental respecto a la percepción por parte de los estudiantes. No obstante, las experiencias desarrolladas nos invitan en conjunto a concluir que existen dos motivaciones principales para la introducción de las metodologías docentes de investigación en la base del espacio docente universitario.

Por una parte, desde el punto de vista institucional, cualquier universidad que aspire a competir en términos de productividad científica, generación y transferencia de conocimientos, ha de inculcar el interés por la investigación en fases tempranas de la carrera de los estudiantes. No hay que olvidar que una de las funciones que imprime carácter universitario (a nivel personal pero también corporativo) es, precisamente, la generación y la patente de conocimiento científico. Esta reflexión nos parece especialmente oportuna en el caso de universidades pequeñas con un fuerte compromiso con el territorio y cuyas aspiraciones deberían pasar, en buena lógica, por la retención de su capital humano más brillante.

Por otra parte, desde el punto de vista personal, resulta obvia la ventaja competitiva que se abre para los estudiantes en el plano socio-laboral. Nos referimos al atractivo que desde la perspectiva empresarial (tal vez también éste debiera constituir uno de los criterios en la selección de los cuadros de la Administración Pública), ofrecen unos recursos humanos con competencias proactivas desarrolladas; esto es, con capacidad de enfrentarse a distintos retos y problemas mediante la aplicación adaptativa de capacidades adquiridas de manera interactiva y experimental durante su formación universitaria. Esta capacitación nos parece imprescindible en unos entornos de trabajo enormemente cambiantes por la intensidad y la velocidad del proceso de digitalización, entre otros factores. Las actitudes y aptitudes proactivas son crecientemente demandadas por un sector empresarial cada vez más tendente a estructuras organizacionales “de red” caracterizadas por su flexibilidad y adaptabilidad (Castells, 2006) así como por una gestión de tipo competencial para la que la polivalencia e 
implicación del capital humano en la toma de decisiones resulta esencial (Brunet et al., 2011, p. 66 y ss.; 363 y ss.). También lo es para distintas áreas de una Administración Pública cada vez más proclive a la incorporación de instrumentos y criterios inspirados en la gestión empresarial (Olías de Lima, 2001).

Bien pensado, el miedo o vértigo a la iniciativa autónoma en el terreno profesional tiene mucho que ver con el miedo al error en el proceder teórico-práctico de la investigación científica. Es decir, el error o incluso simplemente la obtención de resultados que no verifican las hipótesis de partida son al nexo investigación-docencia, lo que la falta de proactividad es al desempeño profesional en distintos ámbitos. Partiendo de este paralelismo hallado en las experiencias docentes que venimos desarrollando, el nexo investigación-docencia emerge no solo como una metodología de aprendizaje naturalmente adaptada a un marco docente más interactivo sino, además, como una arena de experimentación que contribuye a superar actitudes de auto-represión de la iniciativa (ante lo nuevo, ante lo diferente o ante lo desconocido).

Investigar no es otra cosa que indagar y profundizar en la realidad de las cosas para descubrir. Investigar científicamente implica, además, hacerlo siguiendo un protocolo o método en el que el ensayo y el error son dos polos que se retroalimentan sin solución de continuidad (por esto la naturaleza del conocimiento científico es crítica y su base es siempre revisable). Por lo tanto, el error procedimental así como las vicisitudes y complejidad que envuelven el proceso de contraste de hipótesis propio de las investigaciones sociales se convierten en estímulos. Lejos de censurarse socialmente (p.ej. en el contexto del grupo de clase), errores, puntos de fuga y vías de mejora en el proceso de investigación se convierten en estímulos y se valoran positivamente como otro más de los productos del proceso de generación de conocimiento científico. De hecho, lo que a nuestro juicio se desprende de las experiencias descritas es que los errores y limitaciones de los trabajos de los estudiantes contribuyen a visualizar el traspaso de roles que se opera en el aula en un proyecto docente inspirado en el nexo investigación-docencia. Es decir, lo lógico es que cuando los docentes pasamos a ocupar un papel secundario en el desarrollo de las habilidades y las capacidades y el protagonismo se transfiere a los estudiantes, emerjan de manera espontánea las vicisitudes propias de cualquier iniciativa de investigación. Y esto último, como sabemos, implica equivocarnos en las más diversas facetas relacionadas con el diseño y ejecución de la misma. No hay que insistir, por tanto, en que el aprendizaje de lo que "no se puede" y/o "no se debe" hacer es mucho mejor asimilado cuando se realiza de manera autónoma al situarnos ante de un problema de investigación. Lo dicho es aplicable tanto en términos de razonamiento teórico-práctico (metodológico) como particularmente en términos instrumentales (es decir, en referencia a las técnicas de investigación). De aquí, en conclusión, la importancia de valorar los errores en el proceso creativo en lugar de censurarlos como es habitual en un proceso de aprendizaje-evaluación tradicional.

Lo que podría hablarse en relación a los problemas o dificultades encontradas en el desempeño docente bajo este tipo de metodología sería asimismo mucho y variado. Señalaremos, por tanto, lo que resulta más visible en el desarrollo cotidiano de las experiencias, y siempre desde la percepción (necesariamente parcial y limitada) de los docentes.

Un primer aspecto importante que se deriva de la práctica del nexo investigacióndocencia es la desorientación inicial de los estudiantes, asociada a dos factores: 1) al traspaso o asunción de corresponsabilidad en el aprendizaje y 2) a lo extraño de la naturaleza de la labor investigadora en virtud de la experiencia previa de aprendizaje (en niveles preuniversitarios pero también universitarios). El primer factor señalado es, probablemente, común a todas las metodologías activas de aprendizaje y constituye un condicionante que se agudiza en nuestro caso en relación al segundo factor apuntado. Así, es bien sabido que en el 
sistema educativo español la ejecución de un trabajo o de un trabajo en grupo iba poco más allá de la recopilación de información y elaboración de un estado de la cuestión a través, a menudo, de fuentes de fácil acceso o al uso; labor que también frecuentemente lleva asociada la falta de rigor científico en la tarea de documentación. En otras palabras, los estudiantes no saben qué es lo que tienen que hacer y de hecho no esperan tener que hacerlo, simplemente porque las metodologías docentes basadas en este modelo parecen seguir siendo minoritarias. Un ejemplo del problema apuntado lo encontramos en la asignatura Métodos y Técnicas de Investigación social del Grado de GAP en la UJA donde el escollo más importante es la dificultad inicial para definir el tema específico de investigación, un estudio de caso, e insertarlo o contextualizarlo en una problemática social más general. Los estudiantes no dudan en expresar su interés por una determinada cuestión o asunto de la realidad social (dígase la pobreza, la corrupción, etc.) Pero encuentran a menudo gran dificultad para concretar un estudio de caso que alumbre, contribuya o amplíe el conocimiento sobre ese tema general. Por supuesto, no nos referimos ya a que el resultado final logre esto (se produce en pocos casos como de hecho se produce en la investigación profesional en general), sino al hecho de la dificultad de concretar áreas específicas de estudio a través de la formulación de preguntas y objetivos específicos de investigación.

Sobre lo dicho no se deberían pasar por alto algunas implicaciones institucionales: nadie invita, ni mucho menos obliga, a desarrollar este tipo de metodologías (de alto coste en tiempo y esfuerzo para el profesorado y también relativamente para los estudiantes, sobre todo en las fases iniciales de práctica de la misma). En descargo de quien corresponda, tampoco hay que obviar el hecho de que la operatividad y la propia factibilidad de estas metodologías es en buena medida una función del tamaño de los grupos de clase y/o de la carga docente soportada por el profesorado. Ambos factores, como sabemos, suelen no jugar a favor en el sistema universitario español. A resultas, los casos de metodologías interactivas como la planteada conviven ( $\mathrm{y}$ chocan por fuerza, a menudo) con las metodologías tradicionales, fuertemente implantadas aún.

Finalizaremos diciendo que las experiencias descritas se re-perfilan y se adaptan constantemente ya que los propios docentes nos encontramos en una posición de aprendizaje continuo sobre la base de lo hecho. Por citar solo una de las vías de desarrollo y evolución potencial de dichas experiencias, nos encontramos actualmente inmersos en la renovación y adaptación de los soportes mediáticos de los proyectos en virtud de las posibilidades abiertas por la disponibilidad de las tecnologías de la información y la comunicación y sus respectivos formatos de soporte de conocimiento (Hung \& Yuen, 2010; McCarthy, 2010; Barczyk, 2013; Tess, 2013; Piotrowski, 2015; Ivala \& Gachago, 2012; Gunuc \& Kuzu, 2015; Sheeran \& Cummings, 2018). Este aspecto nos parece especialmente importante en un contexto donde la aplicación de las nuevas tecnologías a la enseñanza ejerce gran atractivo sobre y para los proyectos docentes y los estudiantes.

\section{BIBLIOGRAFÍA}

Barczyk, C. (2013): "Facebook in higher education courses: an analysis of students' attitudes, community of practice, and classroom community", International Business and

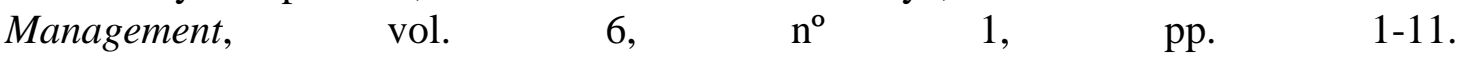
https://doi.org/10.3968/j.ibm.1923842820130601.1165.

Bauman, Z. (2000): Liquid Modernity, Polity, Cambridge.

Bavdekar, S. B., Vyas, S., \& Anand, V. (2018): "Creating Posters for Effective Scientific Communication”, Journal of The Association of Physicians of India, vol. 65, n 8, pp. 82-88.

Beck, U. (1992): Risk Society: Towards a New Modernity, Sage, London. 
Böttcher, F., \& Thiel, F. (2018): "Evaluating research-oriented teaching: a new instrument to assess university students' research competences”, Higher Education, vol. 75, n 1, pp. 91-110. https://doi.org/10.1007/s10734-017-0128-y.

Brew, A. (2003): "Teaching and Research: New relationships and their implications for inquiry-based teaching and learning in higher education”, Higher Education Research \& $\quad$ Development, $\quad$ vol. $\quad 22, \quad \mathrm{n}^{\mathrm{o}} \quad 1, \quad$ pp. $\quad 3-18$. https://doi.org/10.1080/0729436032000056571

Brew, A. (2006): Research and Teaching: Beyond the Divide (Universities into the 21st Century), Palgrave Macmillan, New York.

Brew, A. (2010): "Imperatives and challenges in integrating teaching and research", Higher Education Research \& Development, vol 29, $\mathrm{n}^{\circ} \quad 2$, pp. 139-150. https://doi.org/10.1080/07294360903552451.

Brew, A. (2013): "Understanding the scope of undergraduate research: a framework for curricular and pedagogical decision-making”, Higher Education, vol. 66, $\mathrm{n}^{\circ}$ 5, pp. 603-618. https://doi.org/10.1007/s10734-013-9624-X.

Brunet, I., Belzunegui, A., \& Pastor, I. (2011): Sociología de las Organizaciones, Ed. Universitas, Madrid.

Carbonell, J. (2015): Pedagogías del siglo XXI, alternativas para la innovación educativa, Ed. Octaedro, Barcelona.

Castells, M. (2006): La sociedad red: una visión global, Alianza, Madrid.

Díaz-Barriga, F. (2006): Enseñanza situada: vínculo entre la escuela y la vida, McGraw-Hill, México.

Elton, L. (2001): "Research and Teaching: Conditions for a positive link”, Teaching in Higher Education, vol. 6, no 1, pp. 43-56. https://doi.org/10.1080/13562510020029590.

Fernández, J. A. (2017): Enseñar desde el cerebro del que aprende, Ed. Mayéutica, Madrid.

Galbraith, C. S., \& Merrill, G. B. (2012): "Faculty Research Productivity and Standardized Student Learning Outcomes in a University Teaching Environment: A Bayesian Analysis of Relationships”, Studies in Higher Education, vol. 37, n 4, pp. 469-480. https://doi.org/10.1080/03075079.2010.523782.

Glen, R., Suciu, C., \& Baughn, C. (2014): "The need for design thinking in business schools", Academy of Management Learning \& Education, vol. 13, $\mathrm{n}^{\circ}$ 4, pp. 653-667. https://doi.org/10.5465/amle.2012.0308.

González, C., Guzmán, C., \& Montenegro, H. (2016): “El vínculo docencia-investigación en programas de pregrado: estado del arte y propuestas para fortalecerlo”, Revista de Pedagogía, vol. 37, n 101, pp. 193-213.

Griffin, K. (2001): "Desarrollo humano: origen, evolución e impacto”. En P. Ibarra y K. Unceta (coords.), Ensayos sobre el desarrollo humano, Icaria, Barcelona, pp. 25-40.

Griffiths, R. (2004): "Knowledge production and the research-teaching nexus: the case of the built environment disciplines, Studies in Higher Education, vol. 29, n ${ }^{\circ}$ 6, pp. 709-726. https://doi.org/10.1080/0307507042000287212.

Gunuc, S., \& Kuzu, A. (2015): “Confirmation of campus-class-technology model in student engagement: a path analysis”, Computers in Human Behavior, $\mathrm{n}^{\circ}$ 48, pp. 114-125. https://doi.org/10.1016/j.chb.2015.01.041.

Guzmán-Valenzuela, C., \& Barnett, R. (2013): “Academic Fragilities in a Marketised Age: The Case of Chile”, British Journal of Educational Studies, vol. 61, n 2, pp. 203-220. https://doi.org/10.1080/00071005.2013.776006.

Healey, M. (2005a): "Linking research and teaching: exploring disciplinary spaces and the role of inquiry-based learning”. En R. Barnett (Ed.), Reshaping the University: New Relationships between Research, Scholarship and Teaching, McGraw-Hill/Open University Press, Maidenhead, pp. 67-78. 
Healey, M. (2005b): “Linking Research and Teaching to Benefit Student Learning”, Journal of Geography in Higher Education, vol. 29, $\mathrm{n}^{\circ}$ 2, pp. 183-201. https://doi.org/10.1080/03098260500130387.

Healey, M., Jenkins, A., \& Zetter, R. (2007): Linking teaching and research in disciplines and departments, The Higher Education Academy, York.

Healey, M., Jordan, F., Pell, B., \& Short, C. (2010): “The research-teaching nexus: A case study of students' awareness, experience and perceptions of research”, Innovations in Education and Teaching International, vol. 47, $\mathrm{n}^{\mathrm{0}}$ 2, pp. 235-246. https://doi.org/10.1080/14703291003718968.

Hung, H. T., \& Yuen, S. C. Y. (2010): "Educational use of social networking technology in higher education", Teaching in Higher Education, vol. 15, $\mathrm{n}^{\mathrm{o}}$ 6, pp. 703-714. https://doi.org/10.1080/13562517.2010.507307.

Hunter, A., Laursen, S. L., \& Seymour, E. (2007): "Becoming a scientist: The role of undergraduate research in students' cognitive, personal, and professional development”, Science Education, vol. 91, $\mathrm{n}^{0}$ 1, pp. 36-74. https://doi.org/10.1002/sce.20173.

Hutchings, W. (2007a): Enquiry-Based Learning: Definitions and Rationale, Centre for Excellence in Enquiry-Based Learning, The University of Manchester, Manchester. Recuperado el 29 de marzo de 2019, de https://bit.ly/35l9QCJ.

Hutchings, W. (2007b): The philosophical bases of Enquiry-Based Learning, Centre for Excellence in Enquiry-Based Learning, The University of Manchester, Manchester. Recuperado el 10 de julio de 2019, de https://bit.ly/2XwVWeb.

Ivala, E., \& Gachago, D. (2012): "Social media for enhancing student engagement: the use of Facebook and blogs at a university of technology", South African Journal of Higher Education, vol. 26, n 1, pp. 152-167. https://doi.org/10.20853/26-1-156.

Jenkins, A., Blackman, T., Lindsay, R., \& Paton-Saltzberg, R. (1998): “Teaching and Research: Student Perspectives and Policy Implications”, Studies in Higher Education, vol. 23, n ${ }^{\circ}$ 2, pp. 127-141. https://doi.org/10.1080/03075079812331380344.

Jensen, J. (1988): "Research and Teaching in the Universities of Denmark: does such an interplay really exist?”, Higher Education, $\mathrm{n}^{\mathrm{o}}$ 17, pp. 17-26. https://doi.org/10.1007/BF00130897.

Lacey, A., \& Murray, C. (2015): Rethinking the Regulatory Environment of CompetencyBased Education, AEI Series on Competency-Based Higher Education, American Enterprise Institute for Public Policy Research, Washington.

Lage, M. J., \& Platt, G. (2000): “The Internet and the Inverted Classroom”, Journal of Economic Education, $\mathrm{n}^{0}$ 31(1): 11. https://doi.org/10.1080/00220480009596756.

Lee, J. S., Blackwell, S., Drake, J., \& Moran, K. A. (2014): "Taking a leap of faith: Redefining teaching and learning in higher education through project-based learning”, Interdisciplinary Journal of Problem-Based Learning, vol. 8, $\mathrm{n}^{\mathrm{0}}$ 2, pp. 19-34. http://dx.doi.org/10.7771/1541-5015.1426.

Levin, B. (2011): "Mobilizing research knowledge in education", London Review of Education, vol. 9, n 1, pp. 15-26. https://doi.org/10.1080/14748460.2011.550431.

Levin, B. (2013): “To know is not enough: Research knowledge and its use”, Review of Education, vol. 1, n 1, pp. 2-31. https://doi.org/10.1002/rev3.3001.

Levy, P., \& Petrulis, R. (2012): "How do first-year university students experience inquiry and research, and what are the implications for the practice of inquiry-based learning?”, Studies in Higher Education, vol. 37, $\mathrm{n}^{\mathrm{o}}$ 1, pp. 85-101. https://doi.org/10.1080/03075079.2010.499166.

Martín, G., \& Barba, J. (2016): “¿Qué es la innovación docente? Un cambio en las practicas o de pensamiento docente”, EmásF: revista digital de educación física, nº 38, pp. 7-17. 
McCarthy, J. (2010): "Blended learning environments: using social networking sites to enhance the first year experience”, Australasian Journal of Educational Technology, vol. 26, no 6, pp. 729-740. https://doi.org/10.14742/ajet.1039.

Nussbaum, M. C. (2011): Creating capabilities: the human development approach. Rights, Action, and Social Responsibility, Belknap Press of Harvard University Press, Cambridge, Mass.

O'Flaherty, J., \& Phillips, C. (2015): "The use of flipped classrooms in higher education: A scoping review", The Internet and Higher Education, $\mathrm{n}^{\circ}$ 25, pp. 85-95. https://doi.org/10.1016/j.iheduc.2015.02.002.

Olias de Lima, B. (2001): La Nueva Gestión Pública, Prentice Hall, Madrid.

Pan, W., Cotton, D., \& Murray, P. (2014): "Linking research and teaching: context, conflict and complementarity”, Innovations in Education and Teaching International, vol. 51, no 1, pp. 3-14. https://doi.org/10.1080/14703297.2013.847794.

Piotrowski, C. (2015): "Pedagogical applications of social media in business education". Journal of Educational Technology Systems, vol 43, $\mathrm{n}^{\circ}$ 3, pp. 257-265. https://doi.org/10.1177/0047239515570575..

PNUD (1990): Desarrollo Humano. Informe 1990, Tercer Mundo Editores, Bogotá.

Pons, J., Bartolomé, M. I., \& Sánchez, M. (2018): "La elaboración de pósteres científicos como actividad complementaria a través de la enseñanza virtual en la asignatura de Historia de las Relaciones Laborales”. En A. Molina de Dios et al. (eds.), Investigaciones en Historia Económica, Universitat de les Illes Balears, Palma de Mallorca.

Rossi, T. (2018): "How to design an award-winning conference poster”, LSE Impact Blog. Recuperado el 16 de marzo de 2019, de https://bit.ly/37gCDKx

Sánchez, E. M., Cebrián, M. M., \& Botella, E. (2016): "Nuevas prácticas en historia económica: la elaboración y presentación de un póster académico”. En M. A. Bringas et al. (eds.), Nuevas perspectivas en la Investigación docente de la historia económica, Universidad de Cantabria, Santander.

Santos, M. L., Castejón, J., \& Martínez, F. (2012): "La innovación docente en evaluación formativa y metodología participativa: Un proyecto compartido a raíz de la implantación de los nuevos grados”, Psychology, Society, \& Education, vol. 4, n 1 , pp. 73-86. http://dx.doi.org/10.25115/psye.v4i1.482.

Schapper, J., \& Mayson, S. E. (2010): "Research-led teaching: moving from a fractured engagement to a marriage of convenience", Higher Education Research \& Development, $\quad$ vol. $\quad 29, \quad \mathrm{n}^{\circ} \quad 6, \quad$ pp. https://doi.org/10.1080/07294360.2010.489236.

Sen, A. (1989): “Development as capability expansion”, Journal of Development Planning, vol. $19, \mathrm{n}^{\mathrm{o}} 1$, pp. 41-58.

Sen, A. (2005): "Human rights and capabilities", Journal of Human Development, vol. 6, $\mathrm{n}^{0}$ 2, pp. 151-166. https://doi.org/10.1080/14649880500120491.

Sheeran, N., \& Cummings, D. J. (2018): "An examination of the relationship between Facebook groups attached to university courses and student engagement”, Higher Education, vol. 76, n ${ }^{\circ}$ 6, pp. 937-955. https://doi.org/10.1007/s10734-018-0253-2.

Smyth, L., Davila, F., Sloan, T., Rykers, E., Backwell, S., \& Jones, S. B. (2016): "How science really works: the student experience of research-led education”, Higher Education, vol. 72, n 2, pp. 191-207. https://doi.org/10.1007/s10734-015-9945-z.

Tadesse, T., \& Gillies, R. M. (2015): "Nurturing cooperative learning pedagogies in higher education classrooms: evidence of instructional reform and potential challenges", Current Issues in Education, vol. 18, $\mathrm{n}^{0} 2$. https://cie.asu.edu/ojs/index.php/cieatasu/article/view/1374. 
Tess, P. A. (2013): “The role of social media in higher education classes (real and virtual): a literature review", Computers in Human Behavior, vol. 29, $\mathrm{n}^{0}$ 5, pp. 60-68. https://doi.org/10.1016/j.chb.2012.12.032.

Tuning Project. (2007): Tuning General Brochure, European Commission through the Socrates and Tempus programmes (of the Directorate-General for Education and Culture), Brussels.

UNESCO. (2002): Enhancing global sustainability, position paper and proposals by UNESCO, Preparatory Committee for the World Summit on Sustainable Development (WSSD), 3rd Session 25 March, New York.

Visser-Wijnveen, G. J., van der Rijst, R. M., \& van Driel, J. H. (2016): “A questionnaire to capture students' perceptions of research integration in their courses", Higher Education, vol. 71, nº 4, pp. 473-488. https://doi.org/10.1007/s10734-015-9918-2.

Yew, E. H., \& Goh, K. (2016): "Problem-based learning: an overview of its process and impact on learning", Health Professions Education, vol. 2, $\mathrm{n}^{\circ}$ 2, pp. 75-79. https://doi.org/10.1016/j.hpe.2016.01.004.

Zamorski, B. (2002): "Research-led Teaching and Learning in Higher Education: A case”, Teaching in Higher Education, vol. 7, $\mathrm{n}^{\mathrm{o}}$ 4, pp. 411-427. https://doi.org/10.1080/135625102760553919. 